\title{
sciendo
}

\section{The Differences in Pacing Among Age Groups of Amateur Cross-Country Skiers Depend on Performance}

\author{
by \\ Pantelis T. Nikolaidis ${ }^{1}$, Thomas Rosemann², Beat Knechtle ${ }^{2,3}$
}

\begin{abstract}
Pacing strategies have mainly been investigated for runners, but little is known for cross-country skiers. The aim of the present study was to examine the effects of performance and age on pacing strategies in cross-country skiing. All finishers (women, $n=19,375 ;$ men, $n=86,190)$ in the 'Engadin Ski Marathon' (42 km) between 1998 and 2016 were analysed for the percentage change of speed at $10 \mathrm{~km}$ (Change A), $20 \mathrm{~km}$ (Change B) and $35 \mathrm{~km}$ (Change C). They were classified in performance groups according to quartiles of average race speed (Q1, Q2, Q3 and Q4) and in 5-year age groups $(<20,20-24,25-29 \ldots 85-89$ years $)$. Men were faster than women by $+14.3 \%(15.2 \pm 4.0$ vs. $13.3 \pm 3.3 \mathrm{~km} / \mathrm{h} ; \mathrm{p}<$ $0.001, \eta 2=0.215$ ). A small impact of age group $\times$ performance group interaction on Change A was shown in women ( $p$ $<0.001, \eta 2=0.026)$ and men $(p<0.001, \eta 2=0.025)$, where $Q 1$ augmented and $Q 4$ attenuated the decrease in speed with aging. However, the impact of age group $\times$ performance group interaction on Change $B$ and $C$ was trivial $(p=0.002, \eta 2$ $\leq$ 0.010). Based on these findings, it was concluded that the differences in pacing among age groups depended on the performance level. Thus, the coaches and fitness trainers working with cross-country skiers should advise their athletes to consider both age and performance.
\end{abstract}

Key words: age, endurance, master athlete, winter sport.

\section{Introduction}

Pacing strategy during an endurance event can have a significant impact on overall performance. Abbiss and Laursen (2008) described six different pacing strategies, such as negative, allout, positive, even, parabolic-shaped and variable pacing. Generally, during endurance events, well trained athletes tend to adopt a positive pacing strategy, where the athlete progressively slows after having reached peak speed (Abbiss and Laursen, 2008). Aspects of pacing have preferably been investigated in running events of different distances in track-running from $800 \mathrm{~m}$ to $10,000 \mathrm{~m}$ (Aragón et al., 2016; Thiel et al., 2012; Tucker et al., 2006) and road running races of distance such as 5 $\mathrm{km}$ (Deaner and Lowen, 2016), $10 \mathrm{~km}$ (Lima-Silva et al., 2010), a half-marathon (Hanley, 2015), a marathon (Deaner et al., 2014; Ely et al., 2008;
Haney and Mercer, 2011; Hanley, 2016; March et al., 2011), a $100 \mathrm{~km}$ ultra-marathon (Knechtle et al., 2015; Lambert et al., 2004; Rüst et al., 2015; Tan et al., 2016), a $161 \mathrm{~km}$ ultra-marathon (Hoffman, 2014; Parise and Hoffman, 2011; Tan et al., 2016), a 173 $\mathrm{km}$ ultra-marathon (Kerhervé et al., 2016), in running events of different duration such as a 6hour run (Giovanelli et al., 2016), a 24-hour run (Bossi et al., 2016), and in cross-country running (Esteve-Lanao et al., 2014; Hanley, 2014). However, limited information exists about the effect of sex, age and performance on pacing in cross-country skiing, which is one of the most popular sports in Scandinavia, central Europe and countries with cold climate such as Canada and Russia (Carlsson et al., 2016; Losnegard et al., 2016).

In cross-country skiing, different variables

\footnotetext{
1 - Exercise Physiology Laboratory, Nikaia, Greece.

2 - Institute of Primary Care, University of Zurich, Zurich, Switzerland.

3 - Medbase St. Gallen Am Vadianplatz, St. Gallen, Switzerland.
} 
such as sex, age, a performance level and experience seem to influence pacing strategy (Carlsson et al., 2016; Losnegard et al., 2016). Regarding sex, women and men competing in 10 $\mathrm{km}$ and $15 \mathrm{~km}$ cross-country skiing races held in the World Cup, World Championships, and the Olympic Games demonstrated a positive pacing pattern shown by a decline in velocity from the first to the last lap (Losnegard et al., 2016). In longer cross-country skiing races such as the $90 \mathrm{~km}$ Vasaloppet, women showed a more even pacing profile than men with the same finish time, start group, age, and race experience, with men being faster in the first half of the race and women faster in the second half (Carlsson et al., 2016).

Also, the performance level has an influence on pacing in cross-country skiing. During $10 \mathrm{~km}$ and $15 \mathrm{~km}$ cross-country skiing races in the World Cup, World Championships, and the Olympic Games, slower male skiers were characterized by a quick start relative to their average velocity, with a greater decrease during the race compared with the fastest skiers (Losnegard et al., 2016).

Another aspect that relates to pacing, but has not been studied in cross-country skiers yet, is the effect of age, i.e. whether younger and older skiers differ in pacing. In other sports disciplines such as running and swimming, pacing of different age groups has been investigated. For $100 \mathrm{~km}$ ultramarathoners, it has been shown that younger athletes (i.e. age group 18-24 years) were slower than older athletes and older athletes did not slow down more than younger athletes (Rüst et al., 2015). In master swimmers competing in the 2014 FINA World Masters Championships in $100 \mathrm{~m}, 200$ $\mathrm{m}, 400 \mathrm{~m}$, and $800 \mathrm{~m}$ freestyle in age groups from 25-29 years to 90-94 years, pacing patterns differed by age groups for all distances with younger swimmers showing more even pacing (Nikolaidis and Knechtle, 2017b). On the other hand, it has been shown that older marathon runners adopted a more even pacing strategy than their younger counterparts (March et al., 2011). Thus, pacing in cross-country skiing would be expected to vary by age.

Although the above mentioned studies have improved our understanding of the separate effects of sex, age and performance on pacing in endurance sports, two main gaps in the relevant literature may be identified; first, the effect of age has not been examined in cross-country skiers, and, second, no information about the impact of agexperformance interaction on pacing exists. The information on the effect of age and, particularly, its interaction with the performance level would interest scientists focusing on pacing in endurance sports and coaches working with cross-country skiers in order to optimize their training and competition. Since pacing strategy is an important factor in attaining high performance standards in cross-country skiing (Losnegard et al., 2016), coaches and their athletes should focus on pacing during training considering the specific demands by sex, age and performance. Usually, coaches train athletes in small groups varying for age and performance, e.g. slow cross-country skiers differing for age, thus prescribing age- and performance-tailored exercise is a challenge. Therefore, being aware of the combined effect of age and performance on pacing would assist coaches in developing age- and performancetailored pacing strategies. Despite the body of knowledge on pacing derived from studies on running, cross-country skiing has unique characteristics (e.g. larger muscle activity of upper limbs compared to running, humanxequipment interaction) that may influence age-related differences in performance and pacing (Knechtle and Nikolaidis, 2017). Therefore, the aim of this study was to investigate whether differences in pacing strategies existed between younger and older cross-country skiers competing in a crosscountry skiing race covering the distance of a marathon. Moreover, we aimed to compare the pacing strategy of cross-country skiers with similar performance and different age.

\section{Methods}

\section{Design and procedures}

The institutional review board of St Gallen, Switzerland, approved this study. Since the study involved analysis of publicly available data, the requirement for informed consent was waived. The $42 \mathrm{~km}$ 'Engadin Ski Marathon' is an annually held cross-country ski race taking place on the second Sunday of March in the upper Engadin valley in Switzerland, Europe. Each year, between 11,000 and 13,000 skiers participate in this race. Participation is open to anyone older than 16.

The start of the race takes place in Maloja with an elevation of $1,820 \mathrm{~m}$ above sea level. Split 
times are taken at the time stations in Silvaplana (Change A, $10 \mathrm{~km}, 1,790 \mathrm{~m}$ above sea level), Pontresina (Change B, $20 \mathrm{~km}$, 1,805 m above sea level) and La Punt-Chamues-ch (Change C, $35 \mathrm{~km}$, $1,687 \mathrm{~m}$ above sea level). The finish is in S-chanf at $1,670 \mathrm{~m}$ above sea level.

\section{Participants}

All athletes who finished the 'Engadin Ski Marathon' between 1998 and 2016 were considered. Data with name, age and sex of the athletes were obtained from the publicly available race website of the 'Engadin Skin Marathon' at www.engadin-skimarathon.ch. The initial sample included 105,587 participants. Twenty-two participants, whose information on split times was missing, were excluded from further analysis, resulting in a final sample of 105,565 participants.

\section{Statistical analyses}

Descriptive statistics (mean \pm standard deviation) were used for all variables. We created performance groups according to quartiles of average race speed (Q1, Q2, Q3 and Q4) in total and within each age group. This approach allowed a 'relative' comparison among age groups, e.g. the faster 50-55 years athletes were compared with the faster 20-25 years athletes for pacing; however, we acknowledged that these groups differed for performance. Quartiles have been used previously to study the effect of performance on pacing in marathon runners (Nikolaidis and Knechtle, 2017a; Renfree and St Clair Gibson, 2013; Santos-Lozano et al., 2014) and triathletes (Knechtle and Nikolaidis, 2016). A two-way ANOVA examined the main effects of sex, age group, performance group and split, and the impact of performance group $\times$ split and performance group $\times$ age group interaction on race speed, followed by a Bonferroni post-hoc analysis. The magnitude of differences in the ANOVA was evaluated using eta squared $\left(\eta^{2}\right)$ as trivial $\left(\eta^{2}<0.01\right)$, small $\left(0.01 \leq \eta^{2}<0.06\right)$, moderate $\left(0.06 \leq \eta^{2}<0.14\right)$ and large $\left(\eta^{2} \geq 0.14\right)$. We calculated three percentage changes of speed, Change A $(100 \times($ split2-split1)/split1), Change B (100×(split3-split2)/split2) and Change C (100×(split4-split3)/split3). These changes refer to the time stations (i.e. Silvaplana = Change $\mathrm{A}$, Pontresina $=$ Change $\mathrm{B}$ and La Punt $=$ Change $\mathrm{C}$ ) during the race. The statistical packages IBM SPSS v.20.0 (SPSS, Chicago, USA) and GraphPad Prism v. 7.0 (GraphPad Software, San Diego, USA) were used to perform all statistical analyses. Alpha level was set at 0.05 .

\section{Results}

Sex $\times$ performance group

A large main effect of sex on mean speed was observed $\left(p<0.001, \eta^{2}=0.215\right)$, where men were faster than women by $+14.3 \%$ (15.2 \pm 4.0 vs. $13.3 \pm 3.3 \mathrm{~km} / \mathrm{h})$. Also, a large main effect of performance group on speed was shown $(p<0.001$, $\left.\eta^{2}=0.767\right)$. A small impact of sex×performance interaction on speed was found $\left(p<0.001, \eta^{2}=\right.$ 0.031 ), where sex difference was larger in the faster and smaller in the slower performance groups, i.e. $15.7 \%, 16.3 \%, 14.5 \%$ and $10.4 \%$ in Q1, Q2, Q3 and Q4, respectively (Table 1 ).

In split 1, 2, 3 and 4, similar performanceand sex-related trends as in the overall speed were observed: (i) men were faster than women, (ii) split 3 was the fastest and split 4 the slowest, and (iii) the sex difference decreased with decreasing performance. With regard to changes of speed, the largest effect of performance group was shown in Change $A$ and the lowest in Change $C$. In Change $A$ and $B$, the fastest group (Q1) changed speed the less, especially compared to Q2 and Q3.

Age group $\times$ performance group

Considering the quartiles of all participants, an age group xperformance quartile association was observed, where the prevalence of the fastest quartile (Q1) decreased with increasing age in both women $\left(\chi^{2}=1002.48, p<0.001, \varphi=\right.$ $0.227)$ and men $\left(\chi^{2}=6840.53, p<0.001, \varphi=0.282\right)$ (Figure 1). Thus, we considered only performance quartiles calculated separately for each age group in the subsequent analyses.

The speed of women and men by split expressed as percentage of split $1(100 \%)$ can be seen in Figure 2. A trivial main effect of age group on Change A was observed in women $\left(p<0.001, \eta^{2}\right.$ $=0.006)$ and men $\left(p<0.001, \eta^{2}=0.003\right)$, where the younger group had the smaller change (Figure 3 ). A small impact of age group xperformance group interaction on Change A was shown in women $(p<$ $\left.0.001, \eta^{2}=0.026\right)$ and men $\left(p<0.001, \eta^{2}=0.025\right)$, where Q1 attenuated and Q4 augmented the decrease in speed with aging. In Change B, a trivial main effect of age group was observed in women $\left(p<0.001, \eta^{2}=0.002\right)$ and men $\left(p<0.001, \eta^{2}=0.002\right)$ (Figure 4 ). An impact of age group $\times$ performance group interaction on Change $\mathrm{B}$ was shown in women ( $p=0.002, \eta^{2}=0.002$, trivial magnitude) and 
men $\left(p<0.001, \eta^{2}=0.010\right.$, small magnitude). In Change $C$, a trivial main effect of age group was observed in women $\left(p<0.001, \eta^{2}=0.002\right)$ and men $\left(p<0.001, \eta^{2}=0.002\right)$ (Figure 5). To summarise, the effect of age group on change of speed was trivial and this magnitude was similar in women and men. The magnitude of the effect of age group $\times$ performance group interaction on change of speed was similar in both sexes, except for Change B (larger in men than in women).

To sum up, a small age group xperformance group interaction was observed only in Change A for both women and men and in Change B for men, whereas it was trivial in the other cases.

Table 1

Speed and percentage change of speed by split, performance group and sex.

\begin{tabular}{|c|c|c|c|c|c|c|c|c|c|c|c|}
\hline & \multicolumn{4}{|c|}{ Women } & \multicolumn{4}{|c|}{ Men } & \multicolumn{3}{|c|}{ Effect size $\left(\eta^{2}\right)$} \\
\hline & Q1 & Q2 & Q3 & Q4 & Q1 & Q2 & Q3 & Q4 & Performance & Sex & Interaction \\
\hline $\begin{array}{l}\text { Average } \\
(\mathrm{km} / \mathrm{h})\end{array}$ & $\begin{array}{c}17.7 \pm \\
2.4\end{array}$ & $\begin{array}{c}13.9 \pm \\
0.6\end{array}$ & $\begin{array}{c}12.0 \pm \\
0.6\end{array}$ & $\begin{array}{c}9.4 \pm \\
1.1\end{array}$ & $\begin{array}{c}20.5 \pm \\
2.2\end{array}$ & $\begin{array}{c}16.2 \pm \\
0.8\end{array}$ & $\begin{array}{c}13.7 \pm \\
0.7\end{array}$ & $\begin{array}{c}10.4 \pm \\
1.5\end{array}$ & 0.767 & 0.215 & 0.031 \\
\hline $\begin{array}{l}\text { Split } 1 \\
(\mathrm{~km} / \mathrm{h})\end{array}$ & $\begin{array}{c}17.7 \pm \\
2.2\end{array}$ & $\begin{array}{c}14.5 \pm \\
1.0\end{array}$ & $\begin{array}{c}12.8 \pm \\
1.0\end{array}$ & $\begin{array}{c}10.3 \pm \\
1.6\end{array}$ & $\begin{array}{c}20.0 \pm \\
2.2\end{array}$ & $\begin{array}{c}16.4 \pm \\
1.1\end{array}$ & $\begin{array}{c}14.2 \pm \\
1.1\end{array}$ & $\begin{array}{c}10.3 \pm \\
1.3\end{array}$ & 0.672 & 0.139 & 0.014 \\
\hline $\begin{array}{l}\text { Split } 2 \\
(\mathrm{~km} / \mathrm{h})\end{array}$ & $\begin{array}{c}17.0 \pm \\
2.8\end{array}$ & $\begin{array}{c}13.0 \pm \\
1.0\end{array}$ & $\begin{array}{c}11.1 \pm \\
0.9\end{array}$ & $\begin{array}{c}9.1 \pm \\
1.2\end{array}$ & $\begin{array}{c}20.2 \pm \\
2.6\end{array}$ & $\begin{array}{c}15.4 \pm \\
1.4\end{array}$ & $\begin{array}{c}12.9 \pm \\
1.1\end{array}$ & $\begin{array}{c}10.0 \pm \\
1.4\end{array}$ & 0.692 & 0.184 & 0.035 \\
\hline $\begin{array}{l}\text { Split } 3 \\
(\mathrm{~km} / \mathrm{h})\end{array}$ & $\begin{array}{c}23.2 \pm \\
3.9\end{array}$ & $\begin{array}{c}18.4 \pm \\
2.3\end{array}$ & $\begin{array}{c}15.5 \pm \\
1.9\end{array}$ & $\begin{array}{c}11.4 \pm \\
2.0\end{array}$ & $\begin{array}{c}25.7 \pm \\
3.0\end{array}$ & $\begin{array}{c}20.5 \pm \\
1.9\end{array}$ & $\begin{array}{c}17.5 \pm \\
1.9\end{array}$ & $\begin{array}{c}12.7 \pm \\
2.5\end{array}$ & 0.676 & 0.088 & 0.005 \\
\hline $\begin{array}{l}\text { Split } 4 \\
(\mathrm{~km} / \mathrm{h})\end{array}$ & $\begin{array}{c}12.8 \pm \\
2.1\end{array}$ & $\begin{array}{c}10.1 \pm \\
1.0\end{array}$ & $\begin{array}{c}8.7 \pm \\
0.9\end{array}$ & $\begin{array}{c}6.9 \pm \\
1.0\end{array}$ & $\begin{array}{c}15.3 \pm \\
2.1\end{array}$ & $\begin{array}{c}12.1 \pm \\
1.1\end{array}$ & $\begin{array}{c}10.1 \pm \\
1.0\end{array}$ & $\begin{array}{c}7.6 \pm \\
1.2\end{array}$ & 0.648 & 0.169 & 0.033 \\
\hline $\begin{array}{l}\text { Change } \\
\text { A }(\%)\end{array}$ & $\begin{array}{c}-4.4 \pm \\
10.2\end{array}$ & $\begin{array}{c}-10.1 \pm \\
8.8\end{array}$ & $\begin{array}{c}-12.6 \pm \\
8.2\end{array}$ & $\begin{array}{c}-10.3 \pm \\
12.8\end{array}$ & $\begin{array}{c}1.1 \pm \\
9.4\end{array}$ & $\begin{array}{c}-5.5 \pm \\
10.1\end{array}$ & $\begin{array}{c}-8.9 \pm \\
9.7\end{array}$ & $\begin{array}{c}-9.9 \pm \\
10.9\end{array}$ & 0.071 & 0.018 & 0.005 \\
\hline $\begin{array}{l}\text { Change } \\
\mathrm{B}(\%)\end{array}$ & $\begin{array}{c}38.3 \pm \\
20.6\end{array}$ & $\begin{array}{c}43.3 \pm \\
22.9\end{array}$ & $\begin{array}{c}40.1 \pm \\
21.0\end{array}$ & $\begin{array}{c}26.0 \pm \\
21.3\end{array}$ & $\begin{array}{c}27.9 \pm \\
9.9\end{array}$ & $\begin{array}{c}33.5 \pm \\
14.4\end{array}$ & $\begin{array}{c}36.6 \pm \\
18.8\end{array}$ & $\begin{array}{c}26.7 \pm \\
22.1\end{array}$ & 0.044 & 0.015 & 0.010 \\
\hline $\begin{array}{l}\text { Change } \\
\mathrm{C}(\%)\end{array}$ & $\begin{array}{c}-43.8 \\
\pm 10.2\end{array}$ & $\begin{array}{c}-44.4 \pm \\
9.5\end{array}$ & $\begin{array}{c}-43.1 \pm \\
8.6\end{array}$ & $\begin{array}{c}-38.5 \pm \\
10.4\end{array}$ & $\begin{array}{c}-40.0 \pm \\
6.5\end{array}$ & $\begin{array}{l}-40.6 \\
\pm 7.4\end{array}$ & $\begin{array}{l}-39.0 \\
\pm 9.3\end{array}$ & $\begin{array}{l}-40.4 \\
\pm 7.8\end{array}$ & 0.021 & 0.010 & 0.008 \\
\hline
\end{tabular}

${ }^{*}$ All main effects and interactions were significant at $p<0.001$.
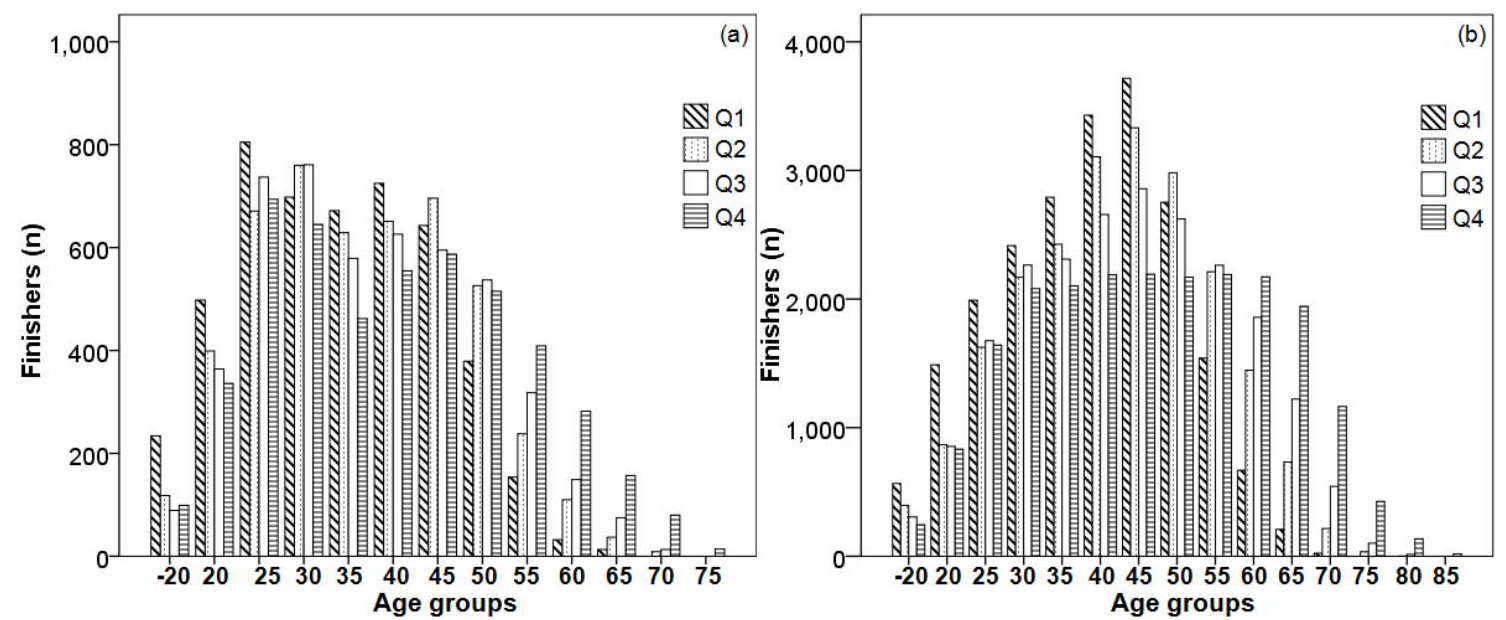

Figure 1

Distribution of overall performance (speed, $\mathrm{km} / \mathrm{h})$ quartiles by age group in women (a) and men (b) 

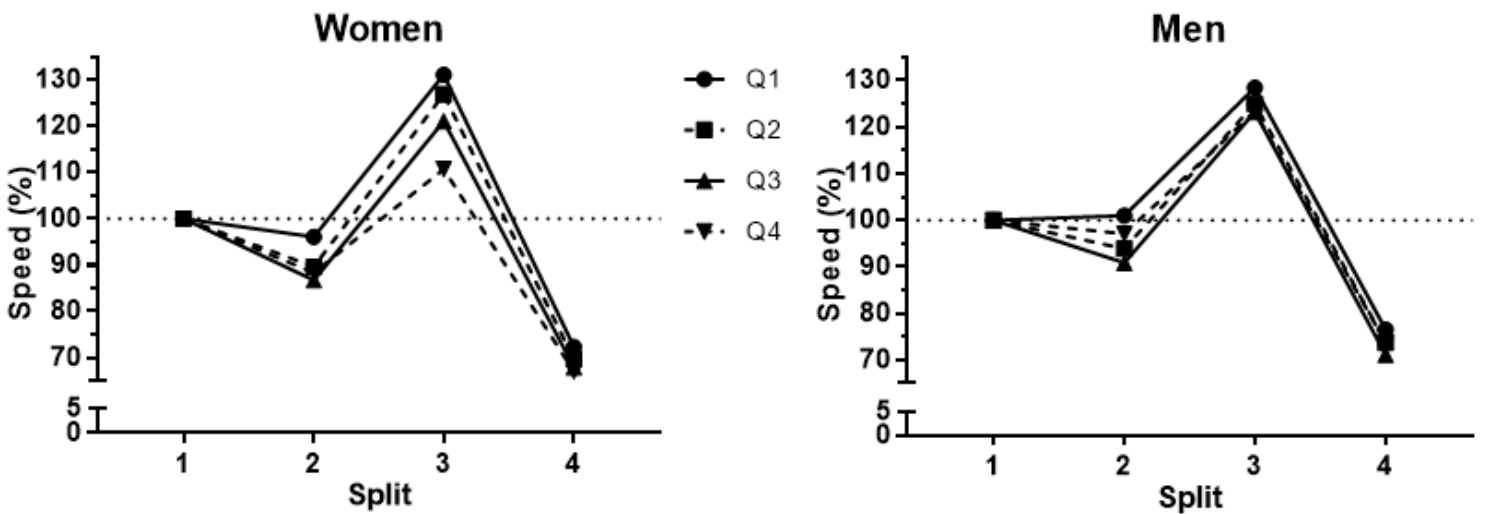

Figure 2

Speed by split expressed as percentage of split $1(100 \%)$ in women and men.

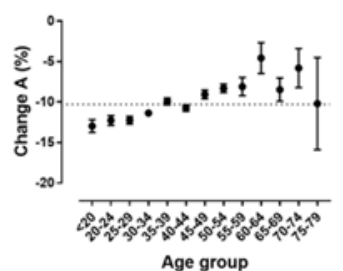

Q1

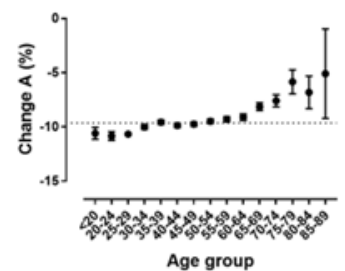

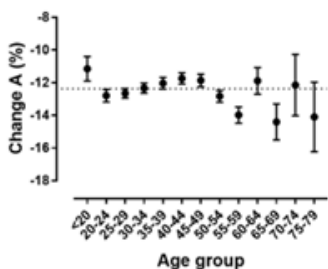

Q2

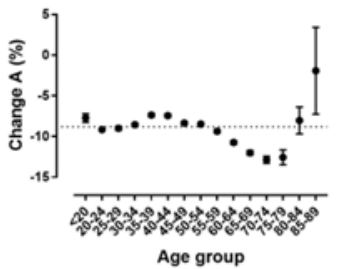

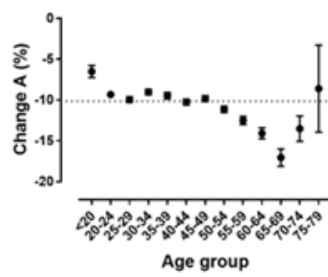

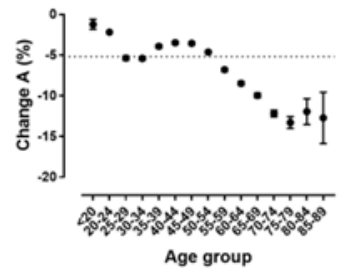

Q4 Women

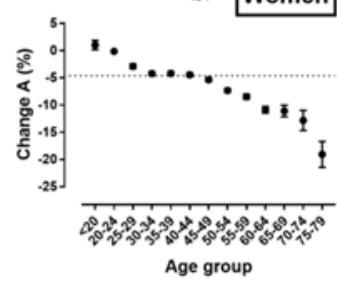

Q4 Men

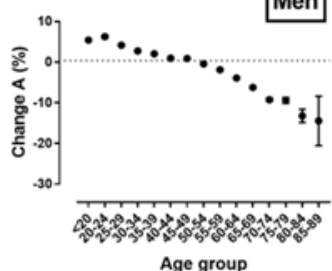

Figure 3

Change in speed from split 1 to split 2 (Change A) by sex, age group and performance group (quartiles). * Error bars represent standard error of the mean. The reference dashed line in $y$ axis represents the mean score of all participants. 
Q1

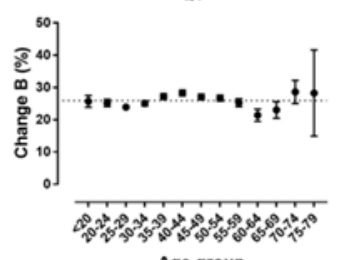

Age group

Q1

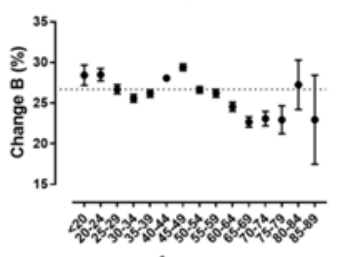

Age group
Q2

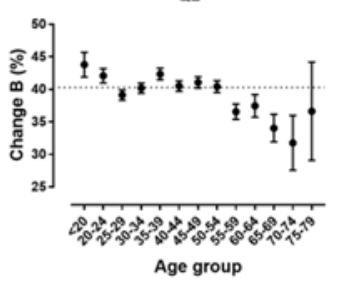

Q2

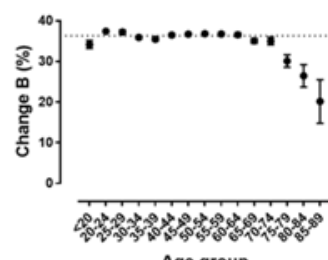

Age group
Q3

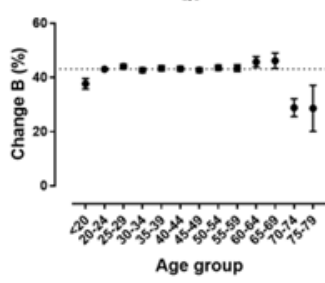

Q3

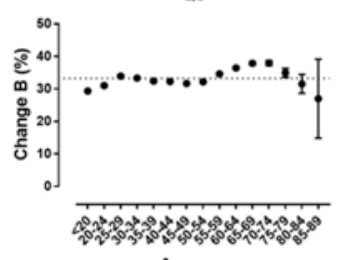

Age group
Q4 Women

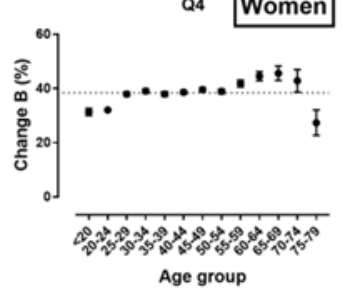

Q4

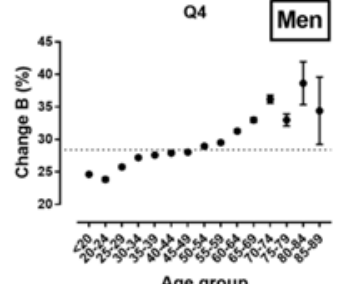

Figure 4

Change in speed from split 2 to split 3 (Change B)

by sex, age group and performance group (quartiles).

* Error bars represent standard error of the mean.

The reference dashed line in y axis represents the mean score of all participants.

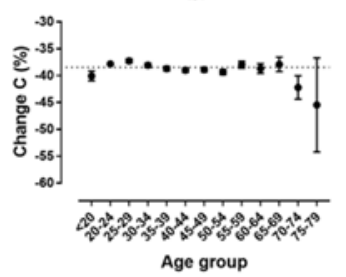

Q1

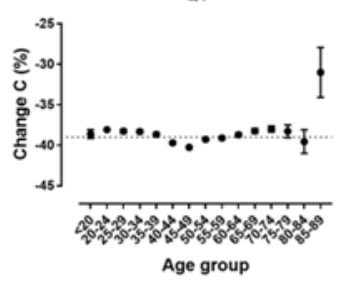

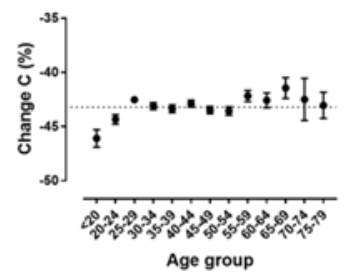

Q2

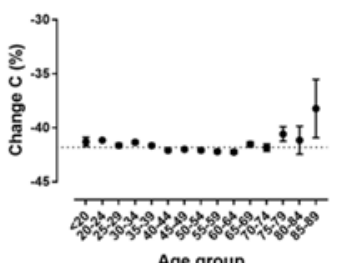

Age group

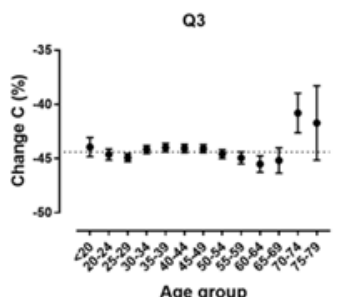

Q3

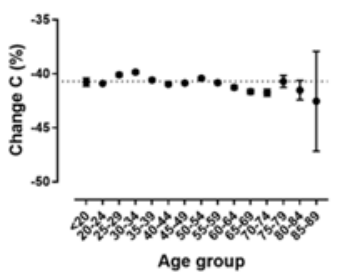

Q4 Women

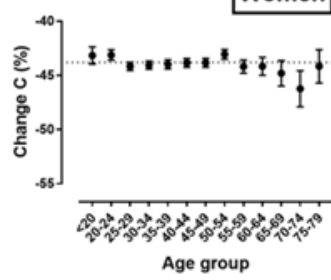

Q4

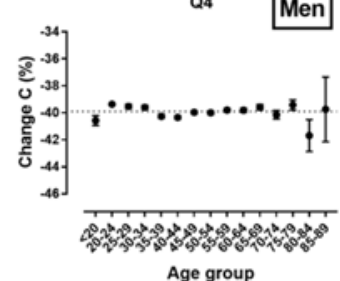

Age group

Figure 5

Change in speed from split 3 to split 4 (Change $C$ ) by sex, age group and performance group (quartiles).

* Error bars represent standard error of the mean.

The reference dashed line in $y$ axis represents the mean score of all participants. 


\section{Discussion}

The main findings of the present study were that (i) men were faster than women and the sex difference was larger in the faster and smaller in the slower performance groups, (ii) the largest effect of performance group was shown in Change $A$ and the lowest in Change $C$, where in Change A and $\mathrm{B}$, the fastest group $(\mathrm{Q} 1)$ changed speed the less, especially compared to Q2 and Q3, and (iii) a small age group $\times$ performance group interaction was observed only in Change A for both women and men and in Change B for men.

Difference in pacing between faster and slower skiers

A major finding was that the fastest skiers (Q1) changed their speed less in the beginning of the race (i.e. Change $\mathrm{A}$ and $\mathrm{B}$ ) compared to slower skiers (Q2 and Q3). Particularly, Q1 was the only group that decreased the least (women) or increased slightly (men) its speed in Change A, whereas the other groups decreased speed. In Change B, Q1 showed the smaller increase of speed compared to Q2 and Q3, which should be attributed to the relatively superior performance of fast skiers in the first two splits.

This finding is most probably due to the hilly course with ascents and descents and the length of the race. The third split has a length of 15 $\mathrm{km}$ and a descent from 1,805 to $1,687 \mathrm{~m}$ above sea level, which might explain that this section was the fastest in the race. The last section has a length of 7 $\mathrm{km}$ and a descent from 1,687 to 1,670 $\mathrm{m}$ above sea level. Most probably the athletes were exhausted after the first $35 \mathrm{~km}$ and therefore not able to increase speed compared to the first split which has also a descent from 1,820 to $1,790 \mathrm{~m}$ above sea level. Another explanation might be that despite the descent during the third split that one would expect to result in increased speed, this split included many changes of altitude (ascents and descents). Such changes in altitude might induce counteracting forces, such as increased potential energy on uphill slopes, air resistance and friction between skis and snow, slowing race speed (Carlsson et al., 2016).

It is well known for runners that high and low performance runners adopt different pacing strategies (Lima-Silva et al., 2010). In female marathoners competing in the Women's Marathon Championship, the fastest runners were the fastest in all segments, and differences in speed between faster and slower athletes increased throughout the race. The fastest runners ran at lower relative speeds than other runners for the first two $5 \mathrm{~km}$ segments, but at higher relative speeds after $35 \mathrm{~km}$ (Renfree and St Clair Gibson, 2013). In athletes competing in Olympic and World Championship marathons, female and male medallists maintained even-paced running from $10 \mathrm{~km}$ onwards, whereas slower finishers dropped off the lead pack at approximately half-distance (Hanley, 2016). Also in athletes competing in World Half Marathon Championships, the best men and women largely maintained their split speeds between $5 \mathrm{~km}$ and 15 $\mathrm{km}$, whereas slower athletes decreased speeds from $5 \mathrm{~km}$ onwards (Hanley, 2015).

Difference in pacing between younger and older skiers

A further important finding was that the fastest skiers attenuated the decrease in speed with increasing age at the beginning of the race (i.e. Change A), whereas the slowest skiers had a more pronounced decrease in speed with increasing age. This observation was of great practical importance, because it indicated that performance groups paced differently according to their age. This observation was partially in agreement with research in marathon running suggesting that the older athletes are better pacers (Nikolaidis and Knechtle, 2017a). This was observed in the present study only for the fast cross-country skiers.

Although the young fast skiers maintained their speed at the beginning, the old fast skiers decreased it. This observation should be attributed to the fact that older fast skiers, despite being the fastest in their age group, were slow compared to the younger fast skiers, and it was a result of age differences in performance (Knechtle and Nikolaidis, 2017); thus, the old fast skiers followed a pacing strategy adopted by slow skiers.

Limitations, strengths and practical implications

The main limitation of the present study was the definition of performance groups, which relied on quartiles. Thus, the comparison of a particular quartile (e.g. Q1) among age groups implied that these groups differed in absolute performance (i.e. race time). Furthermore, large delays in the start might appear due to the large number of participants. On the other hand, the strength of the study was that this "relative" approach in performance allowed the comparison of more even groups. If we had created performance groups according to the race time instead, it would have not been possible to 
consider all age groups, because the older one would have missed very fast race times. Although coaches and cross-country skiers would be more interested in performance analysis by race time groups, the analysis by quartiles provided the opportunity to add theoretical knowledge on differences among age groups. Future studies should examine pacing in the 'Engadin Ski Marathon' using more splits to provide more details on the variation of pacing by sex, age and performance level.

\section{Conclusions}

In summary, previous studies had highlighted the role of sex and performance. Based on the findings of the present study, it was shown that younger fast skiers paced differently compared to older fast skiers. Therefore, sex, age and performance level should be considered by coaches and their athletes in order to adopt an optimum pacing strategy in cross-country skiing. The findings have practical implications for coaches and fitness trainers working with crosscountry skiers, since these professionals prescribe exercise for athletes varying for sex, age and performance. The older fast cross-country skiers had more even pacing than the younger athletes, whereas the older slow cross-country skiers had less even pacing compared to their younger counterparts. Thus, the age-related differences among age groups depend on the performance level, and coaches and fitness trainers should advise their athletes accordingly.

\section{References}

Abbiss CR, Laursen PB. Describing and understanding pacing strategies during athletic competition. Sports Med, 2008; 38: 239-252

Aragón S, Lapresa D, Arana J, Anguera MT, Garzón B. Tactical behaviour of winning athletes in major championship 1500-m and 5000-m track finals. Eur J Sport Sci, 2016; 16: 279-286

Bossi AH, Matta GG, Millet GY, Lima P, Pertence LC, de Lima JP, Hopker JG. Pacing strategy during 24-hour ultramarathon-distance running. Int J Sports Physiol Perform, 2016; 12: 590-596

Carlsson M, Assarsson H, Carlsson T. The influence of sex, age, and race experience on pacing profiles during the $90 \mathrm{~km}$ Vasaloppet ski race. Open Access J Sports Med, 2016; 7: 11-19

Deaner RO, Carter RE, Joyner MJ, Hunter SK. Men are more likely than women to slow in the marathon. Med Sci Sports Exerc,2014; 47: 607-616

Deaner RO, Lowen A. Males and females pace differently in high school cross-country races. J Strength Cond Res, 2016; 30: 2991-2997

Ely MR, Martin DE, Cheuvront SN, Montain SJ. Effect of ambient temperature on marathon pacing is dependent on runner ability. Med Sci Sports Exerc, 2008; 40: 1675-1680

Esteve-Lanao J, Larumbe-Zabala E, Dabab A, Alcocer-Gamboa A, Ahumada F. Running world cross-country championships: A unique model for pacing. Int J Sports Physiol Perform, 2014; 9: 1000-1005

Giovanelli N, Taboga P, Lazzer S. Changes in running Mechanics During a Six Hours Running Race. Int J Sports Physiol Perform, 2016; 12: 642-647

Haney TAJr, Mercer JA. A description of variability of pacing in marathon distance running. Int J Exerc Sci, 2011; 4: 133-140

Hanley B. Senior men's pacing profiles at the IAAF World Cross Country Championships. J Sports Sci, 2014; 32: 1060-1065

Hanley B. Pacing profiles and pack running at the IAAF World Half Marathon Championships. J Sports Sci, 2015; 33: 1189-1195

Hanley B. Pacing, packing and sex-based differences in Olympic and IAAF World Championship marathons. J Sports Sci, 2016; 34: 1675-1681 
Hoffman MD. Pacing by winners of a 161-km mountain ultramarathon. Int J Sports Physiol Perform, 2014; 9: 1054-1056

Kerhervé HA, Cole-Hunter T, Wiegand AN, Solomon C. Pacing during an ultramarathon running event in hilly terrain. PeerJ, 2016; 4: e2591

Knechtle B, Nikolaidis PT. Sex differences in pacing during 'Ultraman Hawaii'. PeerJ, 2016; 4: e2509

Knechtle B, Nikolaidis PT. The age of peak marathon performance in cross-country skiing - The 'Engadin Ski Marathon'. J Strength Cond Res, 2017

Knechtle B, Rosemann T, Zingg MA, Stiefel M, Rust CA. Pacing strategy in male elite and age group $100 \mathrm{~km}$ ultra-marathoners. Open Access J Sports Med, 2015; 6: 71-80

Lambert MI, Dugas JP, Kirkman MC, Mokone GG, Waldeck MR. Changes in Running Speeds in a 100 KM Ultra-Marathon Race. J Sports Sci Med, 2004; 3: 167-173

Lima-Silva AE, Bertuzzi RCM, Pires FO, Barros RV, Gagliardi JF, Hammond J, Kiss MA, Bishop DJ. Effect of performance level on pacing strategy during a 10-km running race. Eur J Appl Physiol, 2010; 108: 10451053

Losnegard T, Kjeldsen K, Skattebo Ø. An analysis of the pacing strategies adopted by elite cross-country skiers. J Strength Cond Res, 2016; 30: 3256-3260

March DS, Vanderburgh PM, Titlebaum PJ, Hoops ML. Age, sex, and finish time as determinants of pacing in the marathon. J Strength Cond Res, 2011; 25: 386-391

Nikolaidis PT, Knechtle B. Do fast older runners pace differently from fast younger runners in the 'new york city marathon'? J Strength Cond Res, 2017a; in print

Nikolaidis PT, Knechtle B. Pacing in age-group freestyle swimmers at The XV FINA World Masters Championships in Montreal 2014. J Sports Sci, 2017b; 35: 1165-1172

Parise CA, Hoffman MD. Influence of temperature and performance level on pacing a $161 \mathrm{~km}$ trail ultramarathon. Int J Sports Physiol Perform, 2011; 6: 243-251

Rüst CA, Rosemann T, Zingg MA, Knechtle B. Do non-elite older runners slow down more than younger runners in a $100 \mathrm{~km}$ ultra-marathon? BMC Sports Sci Med Rehabil, 2015; 7: 1

Renfree A, St Clair Gibson A. Influence of different performance levels on pacing strategy during the Women's World Championship marathon race. Int J Sports Physiol Perform, 2013; 8: 279-285

Santos-Lozano A, Collado PS, Foster C, Lucia A, Garatachea N. Influence of sex and level on marathon pacing strategy. Insights from the New York City race. Int J Sports Med, 2014; 35: 933-938

Tan PL, Tan FH, Bosch AN. Similarities and differences in pacing patterns in a 161-km and 101-km ultradistance road race. J Strength Cond Res, 2016; 30: 2145-2155

Thiel C, Foster C, Banzer W, de Koning J. Pacing in Olympic track races: Competitive tactics versus best performance strategy. J Sports Sci, 2012; 30: 1107-1115

Tucker R, Lambert MI, Noakes TD. An analysis of pacing strategies during men's world-record performances in track athletics. Int J Sports Physiol Perform, 2006; 1: 233-245

\section{Corresponding author:}

\section{Prof. Dr. med. Beat Knechtle}

Gesundheitszentrum St. Gallen

Vadianstrasse 26

9001 St. Gallen

Switzerland

Telefon: +41 (0) 712269300

Telefax: +41 (0) 712269301

E-Mail: beat.knechtle@hispeed.ch 